\title{
Substantial increase in yield predicted by wheat ideotypes for Europe under future climate
}

\author{
Nimai Senapati ${ }^{1, *}$, Simon Griffiths ${ }^{2}$, Malcolm Hawkesford ${ }^{1}$, Peter R. Shewry ${ }^{1}$, \\ Mikhail A. Semenov ${ }^{1}$ \\ ${ }^{1}$ Department of Plant Sciences, Rothamsted Research, West Common, Harpenden, Hertfordshire AL5 2JQ, UK \\ ${ }^{2}$ Department of Crop Genetics, John Innes Centre, Norwich Research Park, Norwich NR4 7UH, UK
}

\begin{abstract}
A substantial increase in food production is needed for global food security. Europe is the largest wheat producer, delivering $35 \%$ of wheat globally, but its future genetic yield potential is yet unknown. We estimated the genetic yield potential of wheat in Europe under 2050 climate by designing in silico wheat ideotypes based on genetic variation in wheat germplasm. To evaluate the importance of heat and drought stresses around flowering, a critical stage in wheat development, sensitive and tolerant ideotypes were designed. Ideotype yields ranged from 9 to $17 \mathrm{t} \mathrm{ha}^{-1}$ across major wheat growing regions in Europe under 2050 climate. Both ideotypes showed a substantial increase in yield of 66-89\% compared to current local cultivars under future climate. Key traits for wheat improvements under future climate were identified. Ideotype design is a powerful tool for estimating crop genetic yield potential in a target environment, along with the potential to accelerate breeding by providing target traits for improvements.
\end{abstract}

KEY WORDS: Climate change - Wheat yield potential - Ideotype design - Crop modeling · Sirius crop model $\cdot$ LARS-WG

\section{INTRODUCTION}

Global food security is under threat from stagnation of crop yields, depleting natural resources and ongoing climate change (FAO et al. 2018). At the same time, future food demand will grow with the increase in the world population to 9.8 billion by 2050 (UN 2017). Increasing food production is one of the most important strategies for delivering global food security, with an estimated increase of 25-70\% being required by 2050 (FAO 2014, Hunter et al. 2017). With limited scope to extend the cropping area, a considerable increase in yield potential is needed to achieve food production targets (Reynolds et al. 2009, Hawkesford et al. 2013). However, raising the crop yield under future climates is challenging, as ongoing climate change would be expected to have negative impacts on crop yields (Trnka et al. 2014, Asseng et al. 2015).

\footnotetext{
${ }^{*}$ Corresponding author: nimai.senapati@rothamsted.ac.uk
}

Crop genetic yield potential is defined as the yield of an optimal genotype that would produce the highest yield in a target environment. Estimation of genetic yield potential would reveal the capacity of increasing yield potential through genetic improvement and germplasm development (Reynolds et al. 2009, Fischer \& Edmeades 2010, Hall \& Richards 2013, Nazim Ud Dowla et al. 2018, Senapati \& Semenov 2020). However, breeding of new cultivars to increase yield potential under future climates is a complicated task, because an understanding in the physiological basis of yield potential in the target environment is required (Donald 1968, Fischer \& Edmeades 2010). The selection of future desirable traits and their optimal combinations in breeding is difficult and often limited by constraints of time and resources. Designing crop ideotypes, based on plant physiology and available genetic variation, not only helps in quantifying genetic yield potential in a target environment

() The authors 2020. Open Access under Creative Commons by Attribution Licence. Use, distribution and reproduction are unrestricted. Authors and original publication must be credited. 
but also accelerates crop breeding by identifying key traits and their optimal combinations for target environments (Donald 1968, Reynolds et al. 2009, Semenov \& Stratonovitch 2013, Ramirez-Villegas et al. 2015, Rötter et al. 2015, Senapati et al. 2019a).

Wheat Triticum aestivum L. is an important staple crop for global food security, providing $20 \%$ of total dietary requirements for calories and protein (Shiferaw et al. 2013). Europe is a major wheat producer, contributing around $35 \%$ of global production (FAOSTAT 2019). Although wheat genetic yield potential has recently been estimated for Europe under current climatic conditions (Senapati \& Semenov 2020), its genetic yield potential under future climates is yet unknown. Therefore, estimating the future genetic yield potential of wheat in Europe is essential for global food security.

In the present study, we designed wheat ideotypes for high yield potentials under future climate in Europe using the well-validated wheat model Sirius (Jamieson et al. 1998b, Senapati et al. 2019b). The main objectives of this study were to (1) estimate the genetic yield potential of wheat in Europe under 2050 climate and (2) identify key traits and their optimal combination for wheat genetic improvements.

\section{MATERIALS AND METHODS}

\subsection{Study sites and current and future climate in Europe}

Thirteen sites across Europe were selected, covering major and contrasting wheat growing regions in Europe, from Spain in the south to Denmark in the north and Hungary in the east to the UK in the west (Fig. S1, Table S1 in the Supplement at www.int-res. com/articles/suppl/c080p189_supp.pdf). Tables S1 \& S2 show site characteristics and local current wheat varieties along with specific characteristics. Thirty years (1981-2010) of daily observed weather were available at each study site. To account for variation in wheat yield due to inter-annual variability in climate and climatic extremes, $100 \mathrm{yr}$ of daily weather data at each site were generated by using a stochastic weather generator (LARS-WG 6.0) (Semenov \& Stratonovitch 2015) based on locally estimated site climatic parameters, hereafter defined as current climate or baseline climate at individual sites, with a corresponding atmospheric $\mathrm{CO}_{2}$ concentration of $364 \mathrm{ppm}$. The mean annual air temperature, annual precipitation and mean daily global radiation of the baseline climate at the study sites ranged from 7.1 to $19.2^{\circ} \mathrm{C}, 344$ to $801 \mathrm{~mm} \mathrm{yr}^{-1}$ and 9.7 to $17.0 \mathrm{MJ} \mathrm{m}^{-2} \mathrm{~d}^{-1}$, respectively (Fig. S1, Table S1). The target future climate in 2050 was based on projections from the global climate model (GCM) HadGEM2 (Collins et al. 2011) from the CMIP5 ensemble for the period 2041-2060 for RCP8.5 (Riahi et al. 2011), with an atmospheric $\mathrm{CO}_{2}$ concentration of $541 \mathrm{ppm}$. RCP8.5 combines assumptions about high population and modest technological improvements, leading to high energy demand, with the highest greenhouse gas concentration and a radiative forcing of $+8.5 \mathrm{~W}$ $\mathrm{m}^{-2}$ by 2100 . At each site, $100 \mathrm{yr}$ of daily weather data for 2050 were generated by using LARS-WG 6.0, hereafter defined as 2050 climate (HadGEM2, RCP8.5). Under 2050 climate, averaged air temperature and global radiation increased by $3.6^{\circ} \mathrm{C}$ and $6 \%$, respectively, compared to baseline climate, whereas annual precipitation decreased by $7 \%$ over the study sites across Europe (Fig. S1).

\subsection{Sirius model}

Sirius is an ecophysiological wheat simulation model with a daily timescale (Jamieson et al. 1998b, Senapati et al. 2019b). Sirius consists of various submodels that describe crop phenological development, soil, water and $\mathrm{N}$ uptake, photosynthesis and biomass production, and partitioning of photosynthates into leaf, stem, grain and root. The model uses daily weather data, a soil physical description, management information and a cultivar description as model inputs. Table S2 shows important cultivar parameters used in Sirius. The model includes the responses of abiotic stresses (e.g. heat and water stresses) and $\mathrm{N}$ limitation on photosynthesis, biomass production and partitioning, grain filling and yield. Sirius includes an optimisation framework, facilitating designing crop ideotypes by optimising cultivar traits in a target environment. In Sirius, soil is described as a cascade of $5 \mathrm{~cm}$ layers up to a user-defined depth. Photosynthesis and biomass production are simulated on a daily time scale as the product of intercepted photosynthetically active radiation and radiation use efficiency (RUE), limited by temperature and water stress. Crop development rate and maturity are governed by phyllochron $\left(P_{h i}\right.$ the time interval between the appearance of successive leaves on a culm, measured in degree-days), day length response $\left(P_{p}\right)$ and duration of grain filling $\left(G_{f}\right)$. The final leaf numbers are determined by combined responses to day length and vernalisation. Canopy is described as a series of leaf layers associated with individual main stem 
leaves. Leaf area development in each layer is simulated by a thermal time sub-model. Leaf senescence is expressed in thermal time and linked to the rank of the leaf in the canopy. Total canopy senescence synchronises with the end of grain filling. N limitation and abiotic stress (temperature or water stresses) could accelerate leaf senescence and thereby reduce photosynthesis and new biomass production. Both heat and water stresses affect photosynthesis and biomass production during the whole crop growing period, and ultimately reduce grain yield. In addition, Sirius also simulates the effects of short spells of heat and drought stresses around flowering on primary fertile grain setting number and size. Sirius was extensively calibrated and validated for many modern wheat cultivars and performed well under diverse climatic conditions across Europe, the USA, Australia and New Zealand, including free-air $\mathrm{CO}_{2}$ enrichment experiments (Jamieson et al. 2000, Semenov \& Shewry 2011, Asseng et al. 2015, 2019). A detailed description of the Sirius model can be found elsewhere (Jamieson et al. 1998b, Stratonovitch \& Semenov 2015, Senapati et al. 2019b).

\subsection{Designing wheat ideotypes}

In the present study, an ideotype was defined as a set of optimised Sirius cultivar parameter values that would deliver maximum yield in a target environment, representing an ideal wheat plant. A cultivar, based on an ideotype and utilising its optimal combination of trait values, would deliver the highest yields for the environment in question. In the present study, local wheat cultivars, viz. Avalon, Cartaya, Claire, Creso, Mercia and Thesee, were used as a site-specific baseline parent for designing wheat ideotypes (Tables S1 \& S2). Primary grain setting number in wheat could be reduced even by a short event of heat and drought stresses around flowering because of the abortion of premature florets, abnormal development of reproductive organs, irreversible abortion of gametophytes and male and female sterility (Prasad \& Djanaguiraman 2014, Onyemaobi et al. 2017). Tolerance to heat and drought stresses around flowering is therefore crucial for maintaining greater primary grain setting number under future climate. To explore the full genetic yield potential under future climate, 2 contrasting ideotypes were designed under 2050 climate in rainfed conditions using a method similar to that of Senapati \& Semenov (2020): heat and drought sensitive around flowering (iS) and heat and drought tolerant around flowering
(iT). Briefly, 2 distinct ideotypes were separately set as highly sensitive (iS) or tolerant (iT) to heat and drought stresses around flowering by assigning 2 different sets of parameters (HSGNT, HSGNR, DSGNT, DSGNS and DSGNRMax) which control sensitivity to heat and drought stresses around flowering (Table S3). These parameter settings for heat and drought sensitivity or tolerance around flowering were based on our previous studies, viz. Stratonovitch \& Semenov (2015), Barber et al. (2017) and Senapati et al. (2019b). These parameters remained unchanged during the subsequent optimisation of 7 other selected cultivar parameters (Table S4), which were optimised in both ideotypes independently under 2050 climate as described in Sections 2.4 and 2.5. The rest of the cultivar parameters in the ideotypes remained the same as those in the respective local current cultivars (Table S2). The detailed target traits and the ideotype optimisation method are provided in the following section.

\subsection{Target traits for designing wheat ideotypes}

A total of 7 cultivar parameters, as mentioned above, related to different wheat cultivar traits (canopy architecture, growth rate, phenological development, response to abiotic stresses) were selected to design wheat ideotypes based on their (1) importance for crop yield improvement under climate change and (2) large observed genetic variations (Semenov \& Stratonovitch 2013). The targeted traits are summarised in Table S4 and described briefly below.

\subsubsection{Canopy structure}

The potential maximum area of flag leaf $\left(A_{\max }\right)$ is a key trait in modifying the rate of canopy expansion and the maximum achievable leaf area index, which in turn will change the pattern of light interception and transpiration demand during the growing season, and therefore affect crop growth and final grain yield (Jamieson et al. 1998b). A larger $A_{\max }$ would help in greater light interception, photosynthesis and grain yield in non-water stress conditions, whereas a smaller $A_{\max }$ could help to avoid drought stress by reducing transpiration and root water uptake. Delaying leaf senescence after flowering is a possible strategy to increase grain yield by extending the duration of leaf senescence and maintaining the green leaf area longer: the so-called stay green $\left(S_{G}\right)$ trait (Christopher et al. 2016). A larger value of $S_{G}$ 
will delay leaf senescence and maintain a green leaf longer after flowering for photosynthesis and grain filling.

\subsubsection{Phenology}

$P_{h}, P_{p}$ and $G_{f}$ are important traits in controlling the rate of phenological development, physiological maturity and yield of wheat (Jamieson et al. 1998b, Semenov \& Stratonovitch 2013). $P_{h}$ is the thermal time required for the appearance of successive leaves, whereas $P_{p}$ is the response of the final leaf number to day length. Both $P_{h}$ and $P_{p}$ are the major drivers of the rate of phenological development and control flowering time. $G_{f}$ is the thermal time needed to be accumulated to complete grain filling. During grain filling, assimilates for the grain are available from 2 sources: (1) new biomass produced from intercepted radiation after flowering and (2) water-soluble or labile carbohydrates stored mostly in the stem before flowering. Thus, increasing $G_{f}$ will increase grain yield by not only increasing the amount of radiation intercepted during grain filling but also increasing the chance of complete relocation of labile carbohydrate into grains. In contrast, decreasing $G_{f}$ will decrease grain yield because of a reduction in the intercepted radiation as well as limitation on the translocation of labile carbohydrate to the grain due to time shortage.

\subsubsection{Root water uptake}

The total quantity and the dynamic pattern of crop root water uptake are important in determining grain yield (Manschadi et al. 2006, Semenov \& Stratonovitch 2013). In Sirius, only a proportion of available soil water can be extracted from each layer in the root zone by the plant on any day, depending on rate of root water uptake $\left(R_{u}\right)$. The proportion of daily water extractable by the plant declines from $10 \%$ at the top of the soil to $R_{u}$ at maximum root length. $R_{u}$ includes direct and indirect impacts, and contributions of root length, overall root architecture and root water uptake efficiency. Faster root water uptake could reduce the current water stress experienced by plants in anticipation of additional available water later in the season but may have penalties under terminal drought. In contrast, an alternative strategy of slower root water uptake might increase yield by conserving water for successful completion of the life cycle in dry environments.

\subsubsection{Tolerance to water stress}

Water stress adversely affects both source and sink strengths in plants throughout the crop growing period or crop duration. Photosynthesis and biomass production are reduced by water stress. The rate of leaf senescence increases under water stress because of the modification in the daily increment of thermal time by a factor termed the maximum acceleration of leaf senescence due to water stress $\left(W_{s S}\right)$. Earlier leaf senescence will reduce grain yield by reducing grain size from not only a reduction in intercepted radiation and photosynthesis, but also a reduction in translocation of the labile plant reserve carbohydrate to the grain due to premature termination of grain filling. A larger $W_{\text {ss }}$ will accelerate leaf senescence under water stress, whereas a smaller $W_{\text {sS }}$ will reduce leaf senescence and help in survival and the tolerance to water stress (Senapati et al. 2019b).

\subsection{Ideotype optimisation under future climate for estimating yield potential}

At each site, both ideotypes (iS and iT) were optimised independently for grain yield under 2050 climate, constrained by available genetic variation in wheat germplasms. The yield of optimal wheat ideotypes under 2050 climate would represent future genetic yield potential (Donald 1968, Reynolds et al. 2009, Fischer \& Edmeades 2010, Hall \& Richards 2013, Ramirez-Villegas et al. 2015, Rötter et al. 2015, Nazim Ud Dowla et al. 2018, Senapati et al. 2019a, Senapati \& Semenov 2020). An evolutionary search algorithm with self-adaptation (EASA) was used in Sirius to optimise cultivar parameters in a highdimensional parameter space for maximum grain yield (Semenov \& Terkel 2003). EASA optimised cultivar parameters by randomly perturbing (mutating) their values and testing their performance in the target environment. At each step of optimisation, 16 new candidate ideotypes were generated from the site-specific baseline parent by perturbing its cultivar parameters randomly within the predefined parameter ranges. Table S4 shows genetic variations in selected traits, as found in the literature for wheat germplasms, and corresponding parameter ranges used in the Sirius model for optimisation. These parameter ranges were based on Sirius calibrations for existing modern wheat cultivars, allowing variations corresponding to the existing genetic variation in wheat germplasms. However, when information 
on observed genetic variation was not available, the parameter range was based on cultivars previously calibrated for Sirius in diverse environments (Jamieson et al. 1998a, Ewert et al. 2002, Lawless et al. 2008, Semenov et al. 2009, Asseng et al. 2015, Martre et al. 2015). For each of the 16 candidates, yields were simulated for $100 \mathrm{yr}$ under the target 2050 climate. Candidates with a coefficient of variation $(\mathrm{CV})$ of yield exceeding $10 \%$ were removed to guarantee high yield stability, whereas a harvest index (HI) of 0.64 was used as the upper limit in wheat (Foulkes et al. 2011). The candidate with the highest mean yield was selected as a parent for the next step. The optimisation process continued until no further improvement in yield potential was possible or parameters converged to an optimal state. To avoid convergence to a local maximum and to fully explore the parameter spaces, we initialised EASA with multiple parents. For each site, we used 25 initial parents randomly scattered in the parameter space, except 1 parent that has the same cultivar parameters as the site-specific baseline cultivar. For each of the 25 initial parents, EASA converges to an optimal combination of parameters; the best was selected as an optimal ideotype for a selected site.

\subsection{Model simulation}

Sirius version 2018 (available at https://sites.google. $\mathrm{com} / \mathrm{view} /$ sirius-wheat) was used for the present study. A common medium soil water profile with a total available water capacity of $177 \mathrm{~mm}$ was used at all sites to eliminate site-specific soil effects from the analysis. Sirius was run first for current local wheat cultivars (Table S2) under baseline and 2050 climate in rainfed conditions to assess yields under present (cv.bs) and future (cv.ft) climate. Then, Sirius was used for designing wheat ideotypes (iS and iT) under 2050 climate in rainfed conditions, using the same sowing dates as those of the current local cultivars. The yields of current wheat cultivars under baseline and future climates were used as references for comparison of yields of ideotypes optimised under 2050 climate. In Sirius, RUE is proportional to atmospheric $\mathrm{CO}_{2}$ concentration with an increase of $30 \%$ for doubling in $\mathrm{CO}_{2}$ concentration compared with the baseline of $364 \mathrm{ppm}$, which agrees with the meta-analysis of different field-scale experiments on the impacts of increased $\mathrm{CO}_{2}$ concentration on crops (Vanuytrecht et al. 2012). A recent study shows that up to $10 \%$ more $\mathrm{C}$ would be assimilated if the Rubisco specificity factor $(\lambda)$ that represents the discrimination between $\mathrm{CO}_{2}$ and $\mathrm{O}_{2}$ is optimal at the current atmospheric $\mathrm{CO}_{2}$ level ( $\mathrm{Zhu}$ et al. 2010). Thus, a $10 \%$ increase in light use efficiency was assumed for wheat ideotypes under 2050 climate. All simulations were assumed to be water limited, but no N limitation was considered. An optimal agronomic management was assumed, i.e. no yield losses due to disease, pests or competition with weeds.

\section{RESULTS AND DISCUSSION}

\subsection{Grain yield of current wheat cultivars under current and future climate}

The simulated mean grain yield of current local wheat cultivars (cv.bs), grown at 13 study sites across Europe (Fig. S1, Table S1), varied from 6 to $10 \mathrm{t} \mathrm{ha}^{-1}$ in rainfed conditions under current climate, with a mean yield of $7.7 \mathrm{t} \mathrm{ha}^{-1}$ (Fig. 1). Clear trends of early flowering (111 d after sowing, DAS) and shorter crop duration (151 d) in southern Europe to late flowering (252 DAS) and longer crop duration (311 d) in northern Europe were found (Figs. 2 \& 3). The highest yield was obtained in northwestern (NW) Europe (Rothamsted, UK; Wageningen, Netherlands), followed by central western (CW) (Clermont-Ferrand and Toulouse, France; Montagnano, Italy) and central eastern (CE) (Halle, Germany; Vienna, Austria; Debrecen, Hungary; Sremska, Serbia) Europe, whereas yield was lowest in northeastern (NE) (Tylstrup, Denmark; Kaunas, Lithuania) and southwestern (SW) (Lleida and Seville, Spain) Europe (Fig. 1). The present study assumed optimal agronomic management that is effective in meeting the $\mathrm{N}$ demand and achieving full control of any weeds, disease and pest infestations, factors that may reduce actual national yields (FAOSTAT 2019). A management-optimal wheat yield potential of $4-13 \mathrm{tha}^{-1}$ has been reported across Europe, whereas actual yields varied from 3 to $12 \mathrm{tha}^{-1}$, with the highest and lowest yields in NW and southern Europe due to the most and least favourable climatic conditions, respectively (Boogaard et al. 2013, FAOSTAT 2019).

Overall, an earlier flowering (by $14 \mathrm{~d}$ ) and a shorter grain filling $(5 \%)$ and crop $(7 \%)$ duration were simulated for current wheat cultivars under 2050 climate (Figs. 2 \& 3). However, a $13 \%$ greater mean wheat yield was predicted for current cultivars under 2050 climate (cv.ft) in Europe (Fig. 1). The increased air temperature under 2050 climate would increase the rate of phenological development of current crop cultivars and reduce crop duration (Wang et al. 2017). 


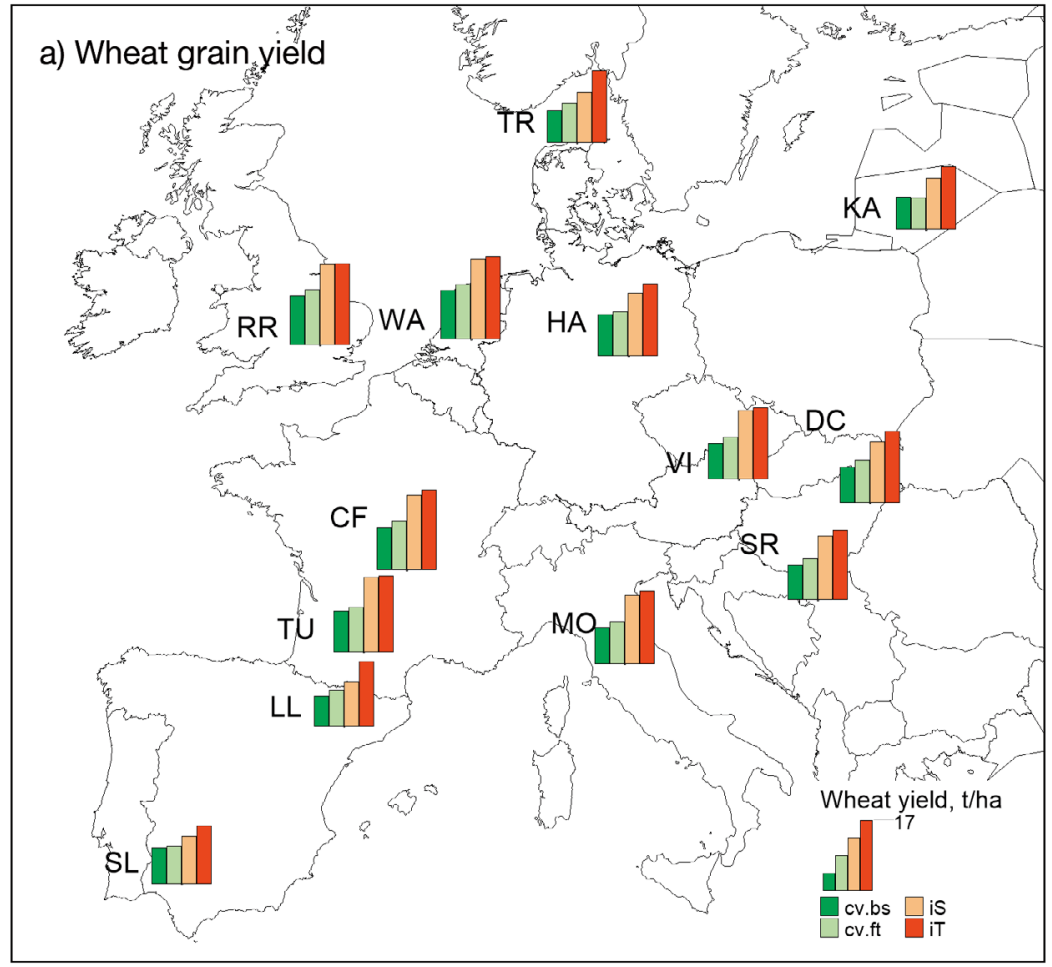

b)

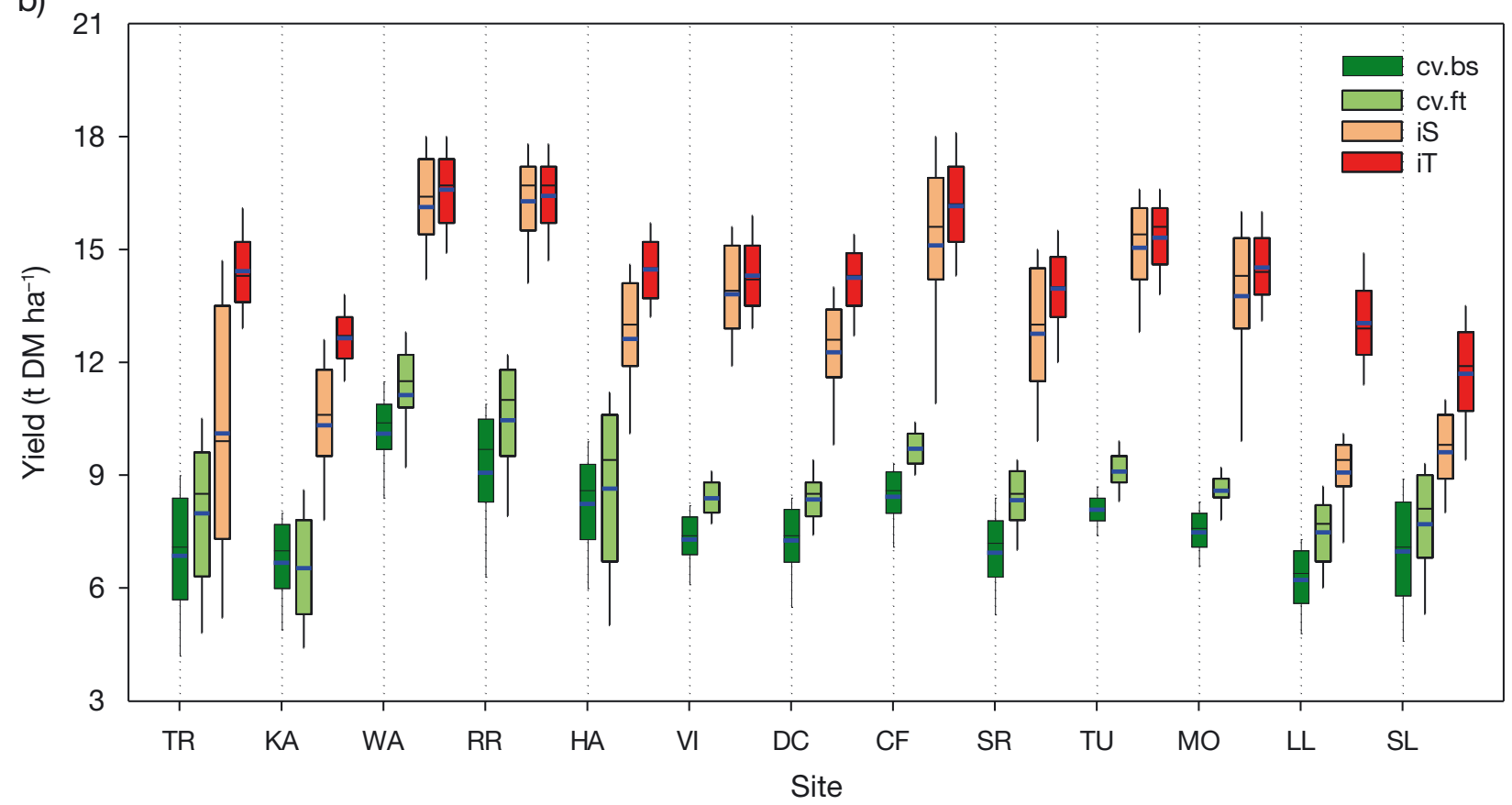

Fig. 1. (a) Simulated grain yield of local wheat cultivars at study sites across major wheat growing regions in Europe under baseline (cv.bs, green) and 2050 (cv.ft, light green) climate, and wheat ideotypes designed as heat and drought sensitive (iS, orange) or tolerant (iT, red) around flowering to achieve high yield potential under 2050 climate. (b) Box plots showing absolute $\left(5^{\text {th }}, 25^{\text {th }}, 50^{\text {th }}, 75^{\text {th }}\right.$ and $95^{\text {th }}$ percentiles) yields, including mean (blue bar), for $100 \mathrm{yr}$ of current local cultivar under baseline (cv.bs) and 2050 (cv.ft) climate, and iS and IT ideotypes under 2050 climate. TR: Tylstrup, Denmark; KA: Kaunas, Lithuania; WA: Wageningen, Netherlands; RR: Rothamsted, UK; HA: Halle, Germany; VI: Vienna, Austria; DC: Debrecen, Hungary; CF: Clermont-Ferrand, France; SR: Sremska, Serbia; TU: Toulouse, France; MO: Montagnano, Italy; LL: Lleida, Spain; SL: 

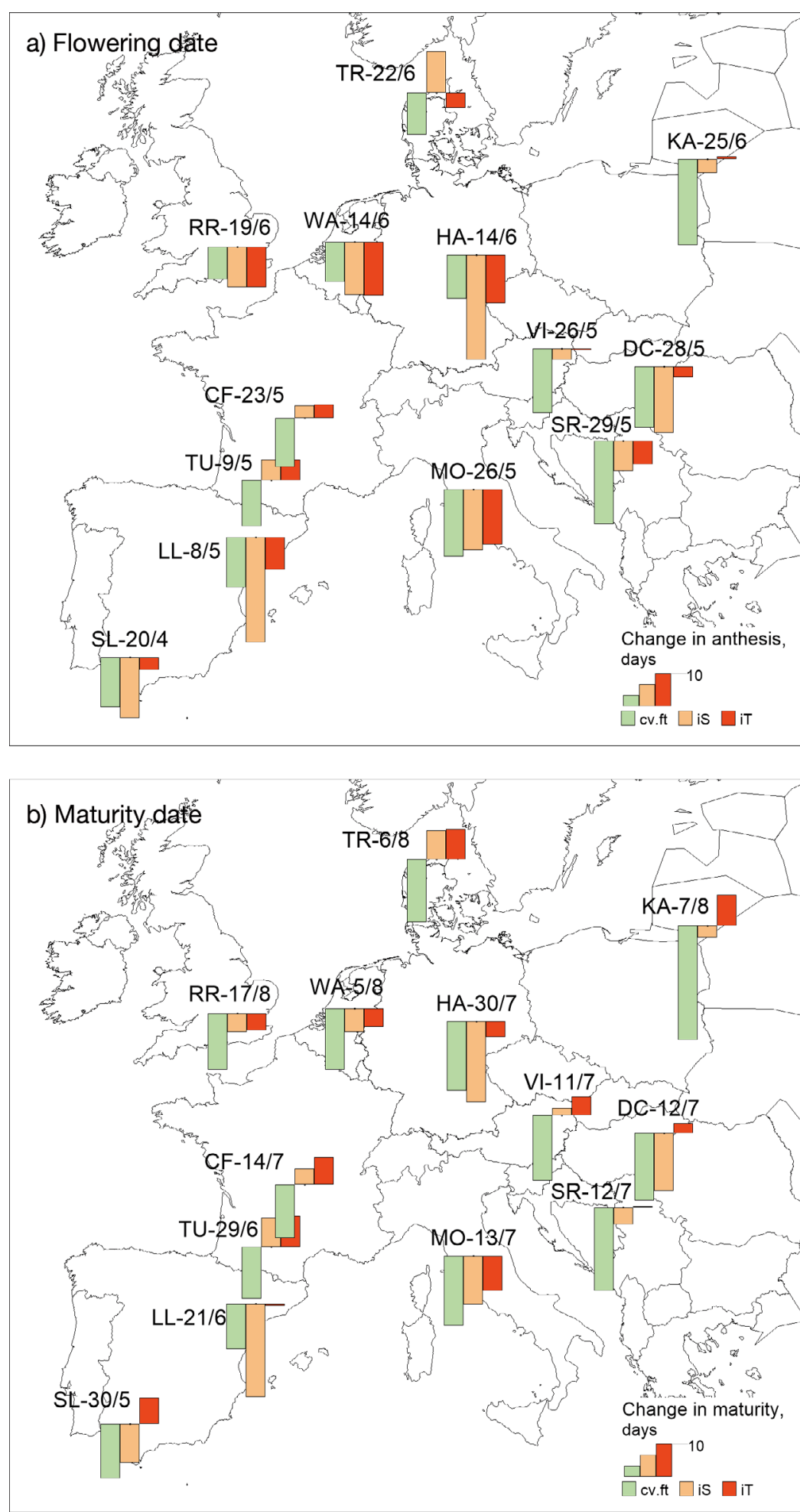

Fig. 2. (a) Flowering and (b) maturity dates of local wheat cultivars across Europe under baseline climate $(\mathrm{d} / \mathrm{mo})$, and change (d) compared to baseline climate in flowering and maturity date of current local cultivars under 2050 climate (cv.ft), and wheat ideotypes designed as heat and drought sensitive (iS) or tolerant (iT) around flowering to achieve high yield potential under 2050 climate. See Fig. 1 for abbreviations
Several studies have predicted a substantial increase in the frequency and intensity of heat and drought stresses under future climates in Europe (e.g. Trnka et al. 2014). However, the present study indicates that the current local cultivars would escape most of the heat and drought stresses by earlier flowering and shorter crop duration under 2050 climate (Figs. 2-4is). Our results show that although a shorter crop duration under future climate would reduce cumulative intercepted radiation $(2.5 \%)$ (Fig. 3), $\mathrm{CO}_{2}$ fertilisation would override the negative impact of reduced intercepted radiation in Europe. Several studies reported negative impacts of increased temperature (Asseng et al. 2015) and changing precipitation (Wang et al. 2017) but benefits of increased $\mathrm{CO}_{2}$ concentration (Vanuytrecht et al. 2012) on wheat yield. In the present study, a small net positive effect of 2050 climate on the grain yield of current wheat cultivars in Europe was predicted when the impacts of temperature, precipitation and $\mathrm{CO}_{2}$ concentration were considered together. Many studies have reported both positive and negative net impacts of climate change on wheat yield in different regions across the world, but most agreed in predicting a positive impact on winter wheat at higher latitudes, for example Europe (Semenov \& Shewry 2011, Asseng et al. 2019).

\subsection{Wheat yield potential estimated by ideotypes under future climate}

A grain yield potential of 9-16 $t \mathrm{ha}^{-1}$ was estimated for optimised wheat ideotype iS under rainfed conditions for 2050 climate in Europe, while a yield potential of 12-17 tha ${ }^{-1}$ was estimated for the iT ideotype (Fig. 1). The mean yields of the iS $\left(12.8 \mathrm{t} \mathrm{ha}^{-1}\right)$ and iT $\left(14.4 \mathrm{t} \mathrm{ha}^{-1}\right)$ ideotypes represent, respectively, 66 and $89 \%$ greater yield potentials compared to current cultivars under baseline climate (cv.bs) and 47 and $67 \%$ greater compared to current cultivars 
a)

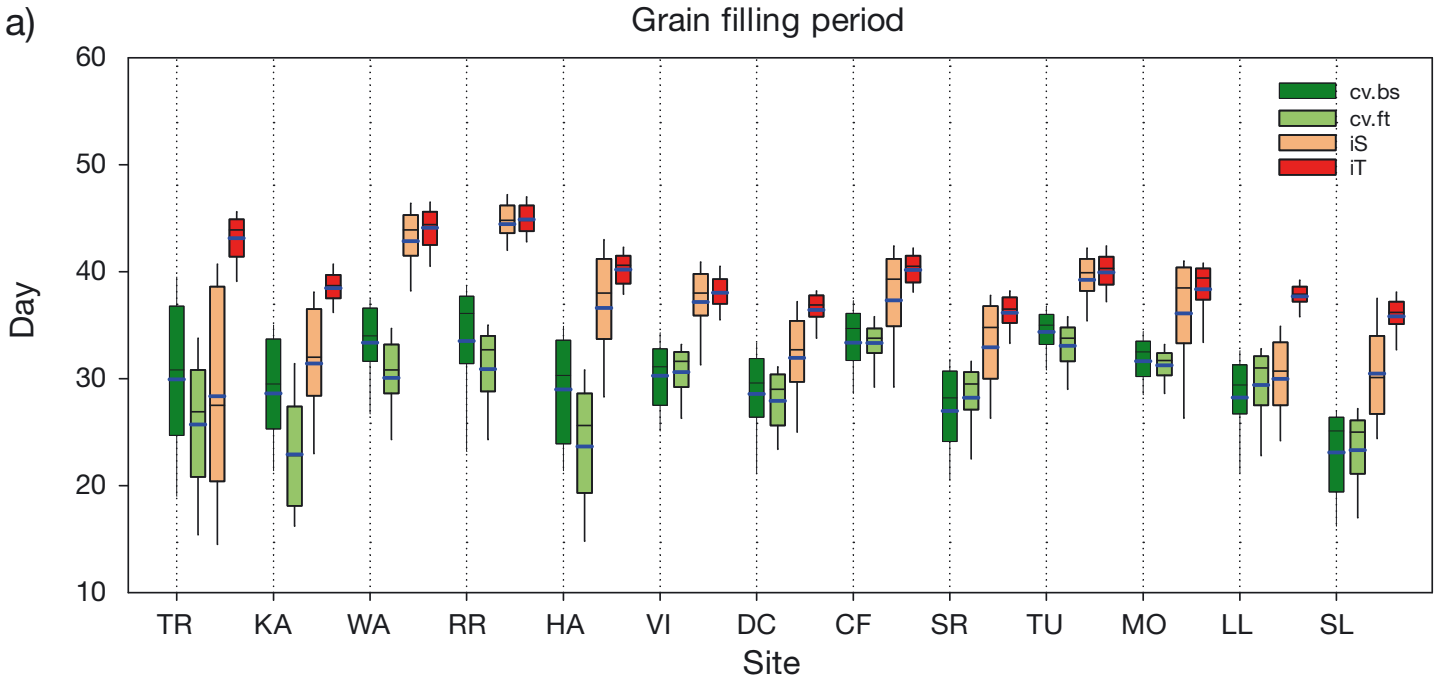

b)

Crop duration

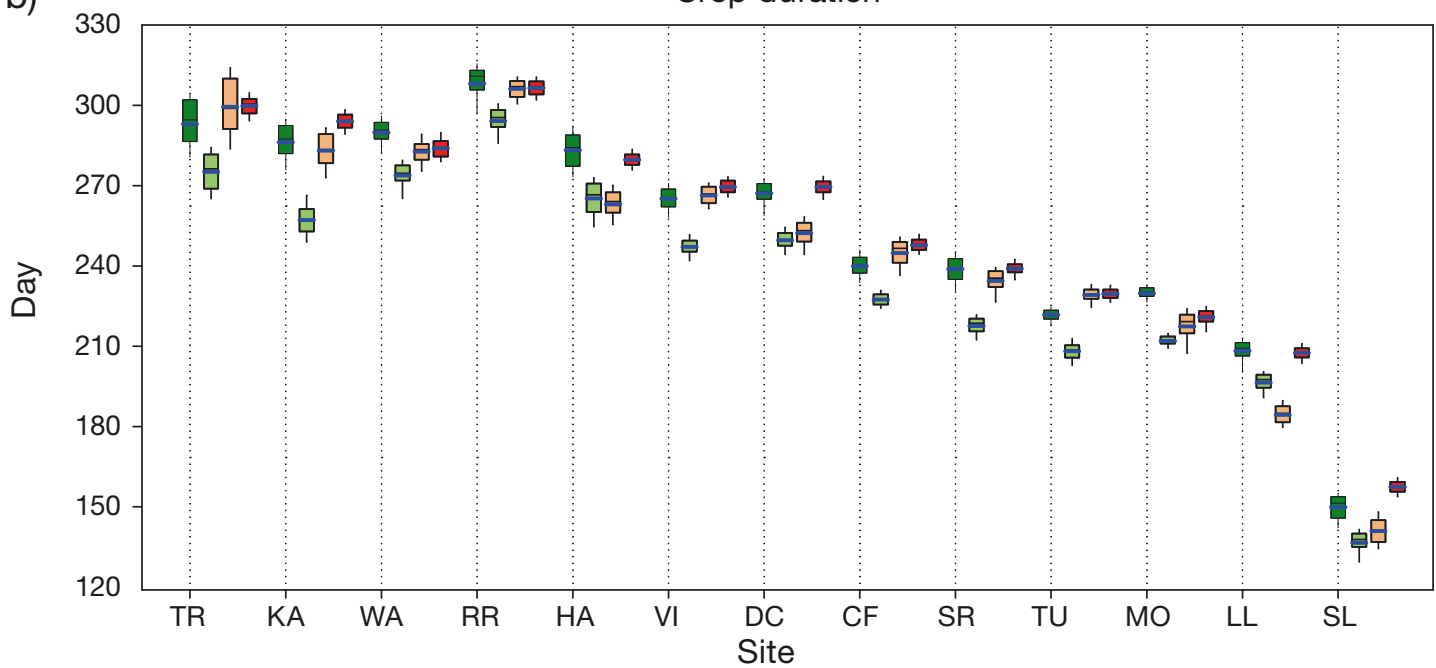

c)

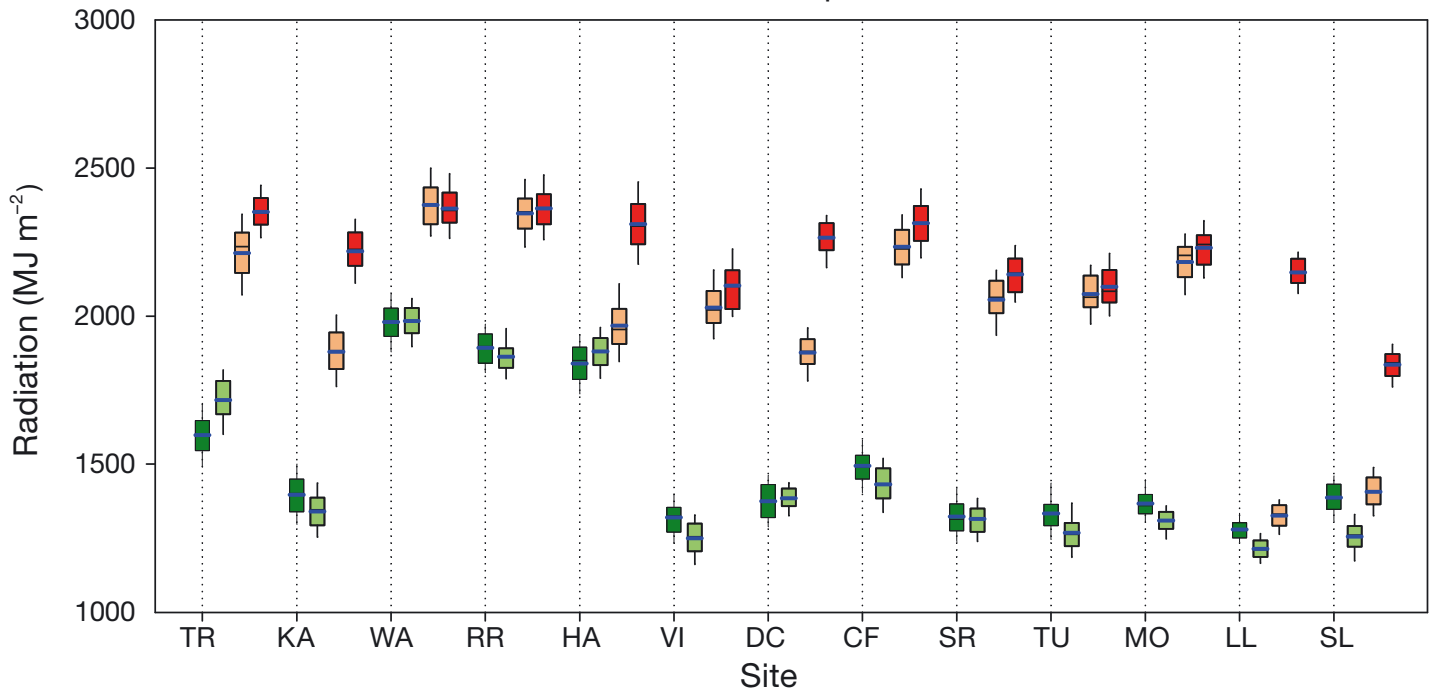

Fig. 3. Boxplot of (a) grain filling duration, (b) crop duration and (c) cumulative intercepted radiation of local wheat cultivars under baseline (cv.bs) and 2050 (cv.ft) climate, and wheat ideotypes designed as heat and drought sensitive (iS) or tolerant (iT) around flowering to achieve high yield potential under 2050 climate. See Fig. 1 for abbreviations and boxplot description 

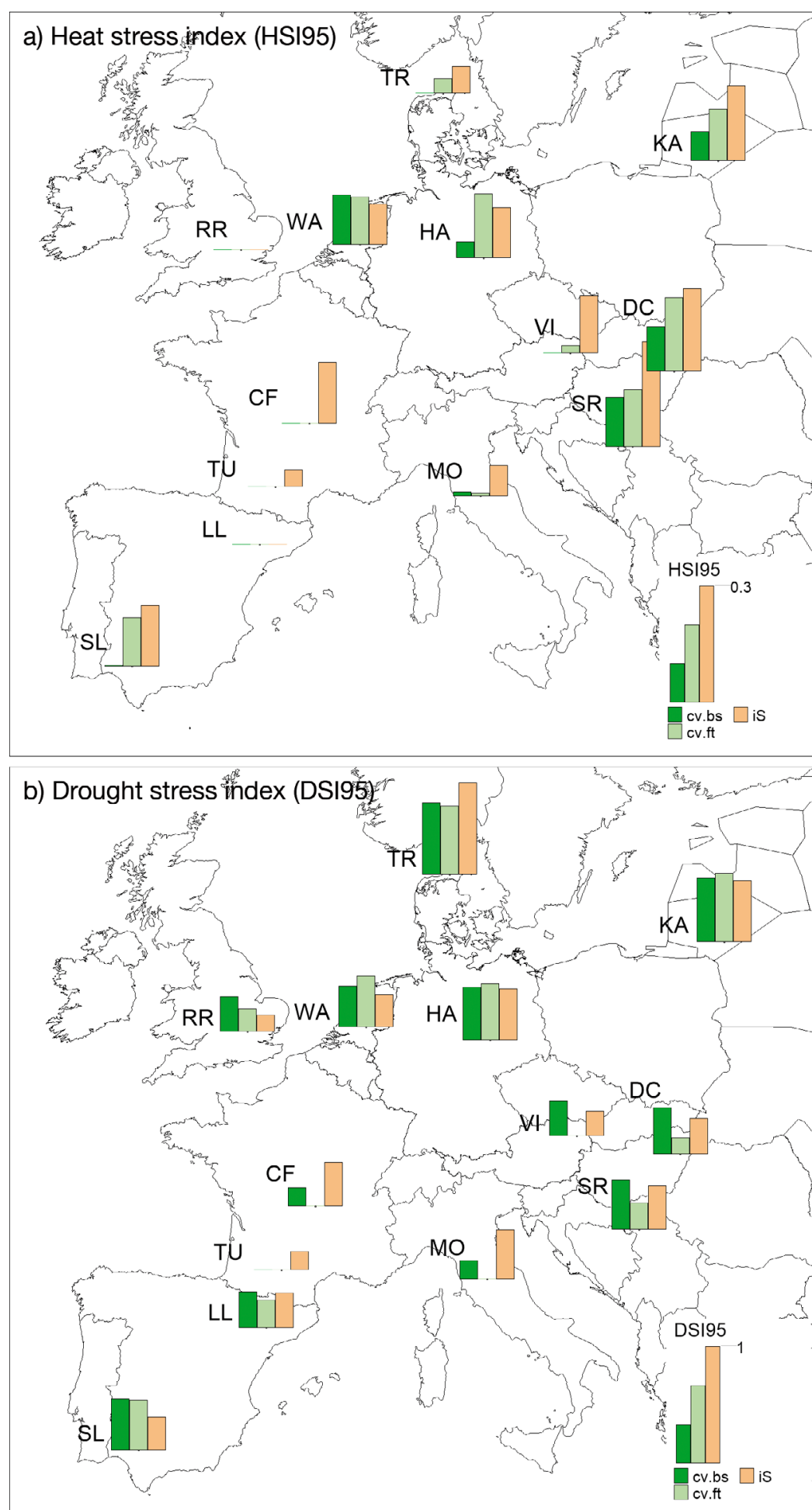

Fig. 4. (a) Heat stress index $\left(95^{\text {th }}\right.$ percentile: HSI95) and (b) drought stress index (95 ${ }^{\text {th }}$ percentile: DSI95) of local wheat cultivars across Europe under baseline (cv.bs) and 2050 (cv.ft) climate, and wheat ideotypes optimised as heat and drought sensitive around flowering (iS) to achieve high yield potential under 2050 climate. $\mathrm{HSI}=\left(1-Y_{\mathrm{wh}} / Y_{\mathrm{w}}\right)$ and DSI $=\left(1-Y_{\mathrm{wd}} / Y_{\mathrm{w}}\right)$, where $Y_{\mathrm{wh}}$ is water-limited yield of wheat sensitive to heat stress around flowering, $Y_{\mathrm{w}}$ is water-limited yield and $Y_{\mathrm{wd}}$ is water-limited yield of wheat sensitive to drought stress around flowering. See Fig. 1 for abbreviations under 2050 climate (cv.ft). Across both ideotypes, the regional wheat yield potentials under 2050 climate follow the same trend as the current cultivars, under both baseline and future climate, viz. $\mathrm{NW}>\mathrm{CW}>\mathrm{CE}>\mathrm{NE} \geq \mathrm{SW}$.

A small number of farmers have occasionally achieved the upper limit of wheat yield potential (up to $17 \mathrm{tha}^{-1}$ ) in recent years in Europe; for example, $16.5 \mathrm{t} \mathrm{ha}^{-1}$ was achieved in 2015 in Northumberland, UK. However, the high yield potentials reported in the present study represent not the best yields possible but the mean stable yields $(\mathrm{CV} \leq 0.10)$ over $100 \mathrm{yr}$, accounting for inter-annual variability in climate and climatic extreme events. Several studies have reported possible wheat yield potentials in the range of 6-20 t ha ${ }^{-1}$ across Europe (Boogaard et al. 2013, Mitchell \& Sheehy 2018). These studies varied from empirical and semi-empirical to process-based modelling with different degrees of detail and complexity. However, in the present study, we estimated yield potential using an advanced well-validated processbased wheat model (Sirius) (Stratonovitch \& Semenov 2015, Senapati et al. 2019b), which incorporates state-ofthe-art knowledge in crop physiology (Table S2) and long- and short-term abiotic stresses (Fig. 4, Tables S2-S5). A recent study has estimated an average wheat genetic yield potential of 11-13 $\mathrm{t} \mathrm{ha}^{-1}$ for Europe under current climatic conditions (Senapati \& Semenov 2020). A slightly greater estimated genetic yield potential of $12-14 \%$ under 2050 climate compared to their study could be due to the $\mathrm{CO}_{2}$ fertilisation effect and relatively better optimised cultivar traits under future climate with the higher atmospheric $\mathrm{CO}_{2}$ concentration. The difference in wheat genetic yield potential at different sites across Europe could be related to differences in the crop growing temperature, precipitation, heat and drought stresses, flowering and maturity time, duration of grain filling and crop growth, and cumulative intercepted ra- 
diation (Figs. 1-4, Figs. S1 \& S2). The possible effect of sowing date on yield was not assessed because of a substantial computational cost considering the number of sites used. However, past studies indicated that changing sowing dates by up to 4 wk has very little effect on yield for iT across Europe, whereas earlier sowing might increase the yield of is, particularly in southern Europe (Semenov \& Stratonovitch 2015).

\subsection{Key traits for wheat improvement under future climate}

\subsubsection{Tolerance to heat and drought stresses around flowering}

An average increase in yield potential of $15 \%$ was estimated for iT compared to iS over the study sites across Europe (Fig. 1). This indicates that tolerance to heat and drought stresses around flowering is an important trait for future wheat adaptation in Europe. However, the benefits of heat and drought tolerance will vary widely across sites. For example, the highest (22-44\%) benefit was predicted under 2050 climate in SW and NE Europe, followed by CE (4-16\%) and CW Europe $(2-7 \%)$. By contrast, almost no (1-3\%) benefit was predicted for NW Europe. Tolerance to heat and drought stresses around flowering has been identified in other studies as an important trait for achieving high wheat yield under future climates, particularly in hot and dry regions (Prasad \& Djanaguiraman 2014, Stratonovitch \& Semenov 2015, Onyemaobi et al. 2017, Senapati et al. 2019b). It is important to note that we found clear differences between heat- and drought-sensitive and heat- and drought-tolerant ideotypes (iS and iT) in optimal canopy structure, phenology, root water uptake and tolerance to water stress (Figs. 2-4, Fig. S2, Table S5), as reported below.

\subsubsection{Optimal canopy structure}

Averaged over study sites, both ideotypes were characterised with an improved canopy structure compared to the baseline current cultivars, in terms of greater flag leaf $A_{\max }(78-113 \%)$ and $S_{G}$ trait (86-113\%), with higher improvement in iT than in iS (Table S5). An optimal canopy architecture is required for maximum interception of solar radiation, photosynthesis and ultimately high yield potential (Hawkesford et al. 2013). A greater $A_{\max }$ resulted in larger leaf areas, which contributed to increased interception of solar radiation and yield for both ideotypes (Fig. S2). The stay-green trait enabled wheat ideotypes to maintain green leaf area longer after flowering for superior photosynthesis during grain filling, resulting in a high yield potential. The importance of the stay-green trait in improving crop yield potential has been reviewed by many researchers, in the presence and absence of heat and drought stresses (Luche et al. 2015).

\subsubsection{Optimal phenology}

The mean flowering time of current wheat cultivars under 2050 climate (cv.ft) was predicted to be $14 \mathrm{~d}$ earlier than at present (cv.bs, Fig. 2). By contrast, the mean optimal flowering time was advanced by $12 \mathrm{~d}$ for ideotype iT compared with cv.ft, except at 3 sites (Rothamsted, UK; Wageningen, Netherlands; and Halle, Germany). On the other hand, the optimal flowering time of ideotype is varied widely across Europe. The optimal flowering time represents a delicate balance between achieving high biomass and maximum primary grain setting at flowering and providing a favourable climate (e.g. cooler temperature) for grain filling. The present study indicates an overall late optimal flowering time under future climate for iT, whereas the optimal flowering time of iS could be early or late depending on the timing of local heat and drought stresses. The optimal flowering time was determined by the optimal phyllochron, the thermal time requirement for successive leaf development $\left(P_{h}\right)$, and the day length response $\left(P_{p}\right)$ (Jamieson et al. 1998b) (Table S5). Thus, optimal flowering time is a crucial trait for adaptation under climate change (Shavrukov et al. 2017).

The averaged simulated grain filling duration of current wheat cultivars (cv.bs) was 30 d under current climate but reduced by $5 \%$ under 2050 climate (cv.ft) (Fig. 3). By contrast, the mean grain filling duration was extended by $24 \%$ (7 d) and $39 \%$ (11 d) compared to cv.ft for iS and iT, respectively. The grain filling duration of iT was $13 \%$ longer than that of iS. Table S5 shows the corresponding duration of grain fillings in terms of thermal time $\left({ }^{\circ} \mathrm{C} \mathrm{d}\right)$ requirement from the beginning of grain filling to the end of grain filling $\left(G_{f}\right)$. Extending the grain filling period is one of the key traits for improving $\mathrm{HI}$ and grain yield, by increasing the intercepted radiation, the production of photosynthates for direct grain filling and the translocation of stored carbohydrates from the vegetative tissues into the grain (Semenov \& Stratonovitch 2013). 
The crop duration (from sowing to maturity) of current cultivars ranged from 151 to $311 \mathrm{~d}$ across Europe (Fig. 3). The mean crop duration of current cultivars was predicted to be reduced by $7 \%$ under 2050 climate mainly because of early flowering and a shorter grain filling duration, resulting in early maturity (Figs. 2 \& 3). The averaged crop duration was extended by $6 \%$ (11 d) and $8 \%$ (18 d) compared to cv.ft for ideotypes iS and iT, respectively, except at 2 sites (Halle, Germany; and Lleida, Spain) only for iS. Averaged over the study sites, the crop duration of iT was $4 \%$ longer than that of iS. A longer crop duration and corresponding late physiological maturity (Figs. $2 \& 3$ ) increased the cumulative intercepted solar radiation (Fig. 3), photosynthesis and final grain yield. However, any adverse weather condition during harvesting might be problematic for late maturity, particularly in Scandinavian countries (Trnka et al. 2011). A warmer future climate (Fig. S1) will result in an increased rate of crop phenological development; however, higher thermal requirements in terms of $P_{h}$ and $G_{f}$ (Table S5) could help to cope with warmer future climates (Wang et al. 2017).

\subsubsection{Root water uptake and tolerance to water stress}

Averaged across sites, a 36-130\% higher optimised value of the parameter rate of root water uptake $\left(R_{u}\right)$ was found for both ideotypes compared to cv.bs, with $R_{u}$ for iS being almost double compared to iT (Table S5). The results imply that a larger root system and optimal root architecture are required for greater root water uptake and production of high biomass and grain yield under future climates. The results also indicate that an improved root system would be a key trait for faster root water uptake to avoid any heat and drought stresses during flowering. A larger and deeper root system is often recommended for increasing plant-available soil water under high drought and heat stresses for avoidance, survival or tolerance (Manschadi et al. 2006). For both ideotypes, the mean optimised value of leaf senescence acceleration due to water stress $\left(W_{s s}\right)$ was reduced by 15-19\% (Table S5), indicating tolerance to drought over the whole crop season would be a key trait for reducing leaf senescence and increasing photosynthesis and yield under water stress conditions in future climates. Recent studies also indicate that overall drought tolerance would be important for future wheat production in Europe (Webber et al. 2018).

\subsection{General discussion}

Several studies have designed ideotypes for maximizing yield potentials of different crops, including wheat, under future climatic conditions (e.g. Tao et al. 2017, Wang et al. 2019). However, most of these studies either did not consider available genetic variation in crop genotypes, or had not optimised cultivar parameters to find a global optimum in a highdimensional cultivar parameter space. The present study is the first of its kind to estimate wheat genetic yield potential by designing ideotypes across major wheat growing regions in Europe under future climate. Wheat ideotypes were optimised for maximum yield under the future local climatic condition by using a universal search optimisation algorithm and utilizing the full ranges of cultivar parameters based on the existing genetic variation in wheat germplasms reported in the literature (Table S4). In the present study, parameter perturbations by EASA were independent from each other in the optimisation process. Nevertheless, once the set of new parameters was sampled, all known interactions and trade-offs between parameters were taken into account within the Sirius model. However, any dependencies or constraints between parameters during perturbations, if known, can be incorporated in the current modelling framework in the same way as we accounted for restrictions in the maximum value of harvest index, $(\mathrm{HI} \leq 0.64)$ or yield coefficient of variation $(\mathrm{CV} \leq 0.10)$. The optimal wheat ideotypes utilise local environmental conditions most efficiently through the best possible crop adaptation under future climate within the limit of available genetic variation. Making the best use of the local environmental conditions, exploiting genetic diversity and plant adaptation are important for increasing crop yield potential under future climates (Lopes et al. 2015).

Wheat ideotypes for 2050 climate were designed using climate projection from a single GCM, HadGEM2, and a single emission scenario, RCP8.5. HadGEM2 is an advanced, well-documented GCM developed by the UK Meteorological Office (Collins et al. 2011), whereas RCP8.5 is the business-as-usual high-emissions scenario (Riahi et al. 2011). The 2050 climate scenario (HadGEM2, RCP8.5) represents the worst-case scenario for Europe, a hot and dry future. For computationally demanding tasks, such as ideotype design, it is not always practical to explore all possible combinations of GCMs and RCPs from the CMIP5 ensemble. In a recent study, it was shown that despite large uncertainties in future climate projections due to GCMs and emission scenarios, it was 
possible to robustly identify target traits for wheat improvement (Semenov \& Stratonovitch 2015). Therefore, the design of wheat ideotypes in the present study could provide a useful roadmap for plant scientists and breeders to identify target traits for crop improvement and genetic adaptation to maximise wheat yield potential under future climates in Europe.

In the last few decades, significant progress has been achieved in identifying quantitative trait loci and underpinning genes associated with most of the above-mentioned identified key traits for wheat improvement and climate change adaptation, along with development of near-isogenic lines with different allelic variations (Langer et al. 2014, Pérez-Gianmarco et al. 2018, Senapati \& Semenov 2020). Additionally, a large natural genetic variation exists for these traits in wheat germplasms (Table S4). The recent developments in modern plant breeding technology also provide the opportunities to develop optimal wheat genotypes for local target environments such as under future climate.

In conclusion, wheat ideotypes, optimised for local environments, predicted a substantial (66-89\%) increase in wheat yields for Europe under 2050 climate (HadGEM2, RCP8.5). Our findings are particularly important considering existing predictions of reduction in global crop yields under climate change and the urgent need to develop new wheat cultivars for future climates in order to achieve global food security. Heat and drought tolerance around flowering, optimal phenology and canopy structure were identified as key traits to achieve such high wheat yields under future climatic conditions in Europe. Other important traits were reduced leaf senescence due to water stress and improved root water uptake. Designing wheat ideotypes and identifying key traits and their optimal combinations, therefore, has the potential to accelerate crop improvement, genetic adaptation and breeding for increased yield potential under global climate change.

Acknowledgements. Rothamsted Research receives grantaided support from the Biotechnology and Biological Sciences Research Council (BBSRC) through Designing Future Wheat (BB/P016855/1) and Achieving Sustainable Agricultural Systems (NE/N018125/1). We are grateful to the reviewers for their constructive comments, which helped to improve the manuscript. The authors declare no conflict of interest.

\section{LITERATURE CITED}

Asseng S, Ewert F, Martre P, Rotter RP and others (2015) Rising temperatures reduce global wheat production. Nat Clim Chang 5:143-147
Asseng S, Martre P, Maiorano A, Rotter RP and others (2019) Climate change impact and adaptation for wheat protein. Glob Change Biol 25:155-173

Barber HM, Lukac M, Simmonds J, Semenov MA, Gooding MJ (2017) Temporally and genetically discrete periods of wheat sensitivity to high temperature. Front Plant Sci 8:51

* Boogaard H, Wolf J, Supit I, Niemeyer S, van Ittersum M (2013) A regional implementation of WOFOST for calculating yield gaps of autumn-sown wheat across the European Union. Field Crops Res 143:130-142

* Christopher JT, Christopher MJ, Borrell AK, Fletcher S, Chenu K (2016) Stay-green traits to improve wheat adaptation in well-watered and water-limited environments. J Exp Bot 67:5159-5172

Collins WJ, Bellouin N, Doutriaux-Boucher M, Gedney N and others (2011) Development and evaluation of an Earth-system model-HadGEM2. Geosci Model Dev 4: 1051-1075

*Donald CM (1968) The breeding of crop ideotypes. Euphytica 17:385-403

* Ewert F, Rodriguez D, Jamieson P, Semenov MA and others (2002) Effects of elevated $\mathrm{CO}_{2}$ and drought on wheat: testing crop simulation models for different experimental and climatic conditions. Agric Ecosyst Environ 93: 249-266

FAO (2014) The state of food and agriculture: innovation in family farming. FAO, Rome

FAO, IFAD, UNICEF, WFP, WHO (2018) The state of food security and nutrition in the world 2018. Building climate resilience for food security and nutrition. FAO, Rome

FAOSTAT (2019) FAOSTAT crop database. FAO, Rome. www.fao.org/faostat/en/\#data/QC

Fischer RAT, Edmeades GO (2010) Breeding and cereal yield progress. Crop Sci 50:S85-S98

Foulkes MJ, Slafer GA, Davies WJ, Berry PM and others (2011) Raising yield potential of wheat. III. Optimizing partitioning to grain while maintaining lodging resistance. J Exp Bot 62:469-486

Hall AJ, Richards RA (2013) Prognosis for genetic improvement of yield potential and water-limited yield of major grain crops. Field Crops Res 143:18-33

*Hawkesford MJ, Araus JL, Park R, Calderini D and others (2013) Prospects of doubling global wheat yields. Food Energy Secur 2:34-48

*Hunter MC, Smith RG, Schipanski ME, Atwood LW, Mortensen DA (2017) Agriculture in 2050: recalibrating targets for sustainable intensification. Bioscience 67 : 386-391

J Jamieson PD, Brooking IR, Semenov MA, Porter JR (1998a) Making sense of wheat development: a critique of methodology. Field Crops Res 55:117-127

Jamieson PD, Semenov MA, Brooking IR, Francis GS (1998b) Sirius: a mechanistic model of wheat response to environmental variation. Eur J Agron 8:161-179

Jamieson PD, Berntsen J, Ewert F, Kimball BA and others (2000) Modelling $\mathrm{CO}_{2}$ effects on wheat with varying nitrogen supplies. Agric Ecosyst Environ 82:27-37

Langer SM, Longinand CFH, Wurschum T (2014) Flowering time control in European winter wheat. Front Plant Sci 5:537

Lawless C, Semenov MA, Jamieson PD (2008) Quantifying the effect of uncertainty in soil moisture characteristics on plant growth using a crop simulation model. Field Crops Res 106:138-147 
Lopes MS, El-Basyoni I, Baenziger PS, Singh S and others (2015) Exploiting genetic diversity from landraces in wheat breeding for adaptation to climate change. J Exp Bot 66:3477-3486

Luche HD, da Silva JAG, da Maia LC, de Oliveira AC (2015) Stay-green: a potentiality in plant breeding. Cienc Rural 45:1755-1760

Manschadi AM, Christopher J, deVoil P, Hammer GL (2006) The role of root architectural traits in adaptation of wheat to water-limited environments. Funct Plant Biol 33:823-837

Martre P, He J, Le Gouis J, Semenov MA (2015) In silico system analysis of physiological traits determining grain yield and protein concentration for wheat as influenced by climate and crop management. J Exp Bot 66:3581-3598

Mitchell PL, Sheehy JE (2018) Potential yield of wheat in the United Kingdom: how to reach $20 \mathrm{t} \mathrm{ha}^{-1}$. Field Crops Res 224:115-125

Nazim Ud Dowla MAN, Edwards I, O'Hara G, Islam S, Ma W (2018) Developing wheat for improved yield and adaptation under a changing climate: optimization of a few key genes. Engineering 4:514-522

Onyemaobi I, Liu H, Siddique KHM, Yan GJ (2017) Both male and female malfunction contributes to yield reduction under water stress during meiosis in bread wheat. Front Plant Sci 7:2071

* Pérez-Gianmarco TI, Slafer GA, Gonzalez FG (2018) Wheat pre-anthesis development as affected by photoperiod sensitivity genes (Ppd-1) under contrasting photoperiods. Funct Plant Biol 45:645-657

Prasad PVV, Djanaguiraman M (2014) Response of floret fertility and individual grain weight of wheat to high temperature stress: sensitive stages and thresholds for temperature and duration. Funct Plant Biol 41:1261-1269

Ramirez-Villegas J, Watson J, Challinor AJ (2015) Identifying traits for genotypic adaptation using crop models. J Exp Bot 66:3451-3462

Reynolds M, Foulkes MJ, Slafer GA, Berry P, Parry MAJ, Snape JW, Angus WJ (2009) Raising yield potential in wheat. J Exp Bot 60:1899-1918

Riahi K, Rao S, Krey V, Cho C and others (2011) RCP 8.5-a scenario of comparatively high greenhouse gas emissions. Clim Change 109:33-57

Rötter RP, Tao F, Höhn JG, Palosuo T (2015) Use of crop simulation modelling to aid ideotype design of future cereal cultivars. J Exp Bot 66:3463-3476

Semenov MA, Shewry PR (2011) Modelling predicts that heat stress, not drought, will increase vulnerability of wheat in Europe. Sci Rep 1:66

Semenov MA, Stratonovitch P (2013) Designing high-yielding wheat ideotypes for a changing climate. Food Energy Secur 2:185-196

Semenov MA, Stratonovitch P (2015) Adapting wheat ideotypes for climate change: accounting for uncertainties in CMIP5 climate projections. Clim Res 65:123-139

Semenov MA, Terkel DA (2003) Analysis of convergence of an evolutionary algorithm with self-adaptation using a stochastic Lyapunov function. Evol Comput 11:363-379
Semenov MA, Martre P, Jamieson PD (2009) Quantifying effects of simple wheat traits on yield in water-limited environments using a modelling approach. Agric For Meteorol 149:1095-1104

Senapati N, Semenov MA (2020) Large genetic yield potential and genetic yield gap estimated for wheat in Europe. Glob Food Secur 24:100340

Senapati N, Brown HE, Semenov MA (2019a) Raising genetic yield potential in high productive countries: designing wheat ideotypes under climate change. Agric For Meteorol 271:33-45

* Senapati N, Stratonovitch P, Paul MJ, Semenov MA (2019b) Drought tolerance during reproductive development is important for increasing wheat yield potential under climate change in Europe. J Exp Bot 70:2549-2560

Shavrukov Y, Kurishbayev A, Jatayev S, Shvidchenko V and others (2017) Early flowering as a drought escape mechanism in plants: How can it aid wheat production? Front Plant Sci 8:1950

* Shiferaw B, Smale M, Braun HJ, Duveiller E, Reynolds M, Muricho G (2013) Crops that feed the world 10. Past successes and future challenges to the role played by wheat in global food security. Food Secur 5:291-317

Stratonovitch P, Semenov MA (2015) Heat tolerance around flowering in wheat identified as a key trait for increased yield potential in Europe under climate change. J Exp Bot 66:3599-3609

Tao FL, Rotter RP, Palosuo T, Diaz-Ambrona CGH and others (2017) Designing future barley ideotypes using a crop model ensemble. Eur J Agron 82:144-162

* Trnka M, Olesen JE, Kersebaum KC, Skjelvag AO and others (2011) Agroclimatic conditions in Europe under climate change. Glob Change Biol 17:2298-2318

* Trnka M, Rotter RP, Ruiz-Ramos M, Kersebaum KC, Olesen JE, Zalud Z, Semenov MA (2014) Adverse weather conditions for European wheat production will become more frequent with climate change. Nat Clim Chang 4 : 637-643

UN (2017) World population prospects: the 2017 revision. UN Department of Economic and Social Affairs, Population Division, New York, NY. https://population.un.org/wpp/

* Vanuytrecht E, Raes D, Willems P, Geerts S (2012) Quantifying field-scale effects of elevated carbon dioxide concentration on crops. Clim Res 54:35-47

* Wang B, Liu DL, Asseng S, Macadam I, Yu Q (2017) Modelling wheat yield change under $\mathrm{CO}_{2}$ increase, heat and water stress in relation to plant available water capacity in eastern Australia. Eur J Agron 90:152-161

* Wang B, Feng PY, Chen C, Liu DL, Waters C, Yu Q (2019) Designing wheat ideotypes to cope with future changing climate in south-eastern Australia. Agric Syst 170: 9-18

*Webber H, Ewert F, Olesen JE, Muller C and others (2018) Diverging importance of drought stress for maize and winter wheat in Europe. Nat Commun 9:4249

Zhu XG, Long SP, Ort DR (2010) Improving photosynthetic efficiency for greater yield. Annu Rev Plant Biol 61: 235-261

Submitted: January 7, 2020; Accepted: May 4, 2020

Proofs received from author(s): June 15, 2020
Editorial responsibility: Nils Chr. Stenseth, Oslo, Norway 